\title{
DESAFIOS NA EDUCAÇÃO BILÍNGUE DE SURDOS: relações que professores estabelecem com o ensino de língua portuguesa escrita para surdos
}

\author{
Hector Renan da Silveira Calixto' \\ Amélia Escotto do Amaral Ribeiro² \\ Alexandre do Amaral Ribeiro ${ }^{3}$
}

\section{RESUMO}

Apenas em tempos recentes, foram propostas ações, voltadas à promoção de mudanças nas relações sociais com as pessoas com deficiência em uma perspectiva inclusiva. Em relação ao surdo e a surdez, do ponto de vista histórico, as percepções deslocam-se da concepção de surdez como doença para a ideia de diferença, oscilando entre a caracterização da surdez como restrição e o reconhecimento de educabilidade e potencialidades do sujeito surdo. A busca de metodologias, estratégias e atendimento educacional, voltados especificamente para surdos, exemplificam os avanços dessa discussão. No contexto escolar é relevante compreender a visão que professores têm do surdo, da sua participação nas atividades escolares e das formas específicas de ensino. Este artigo reflete sobre

\footnotetext{
1 Mestre em Educação, Cultura e Comunicação em Periferias Urbanas (PPGECC/UERJ/RJ). Pós-graduado (lato sensu) em Língua Brasileira de Sinais - Libras (UNIASSELVI/SC) e Docência no Ensino Superior (UNIASSELVI/SC). Licenciado em Pedagogia (FLATED/CE) e Bacharel em Sistemas de Informação (IESAM/PA). Professor Auxiliar do Instituto de Ciências da Educação da Universidade Federal do Oeste do Pará (ICED/UFOPA), na área de Língua Brasileira de Sinais - Libras. Orcid ID: https://orcid.org/0000-0002-4227-6625. E-mail: hectorscalixto@gmail.com

2 Graduação em Pedagogia pela Universidade Regional do Noroeste do Estado do Rio Grande do Sul (1980), Mestrado em Filosofia pela Pontifícia Universidade Católica do Rio de Janeiro (1989), Mestrado em Educação pela Pontifícia Universidade Católica do Rio de Janeiro (1984) e Doutorado em Educação pela Pontifícia Universidade Católica do Rio de Janeiro (2000). Professora Associada da Universidade do Estado do Rio de Janeiro (UERJ/FEBF). Professora no Programa de Pós-Graduação em Educação, Cultura e Comunicação em Periferias Urbanas (PPGECC/UERJ). Orcid ID: https://orcid.org/0000-00016218-4173. E-mail: febf.gelcs@gmail.com

3 Graduação em Letras (Português - Alemão) pela UERJ (1996). Especialização em Psicopedagogia Diferencial: diferenças na aprendizagem pela PUC-Rio (1998). Mestrado em Letras (área de concentração: Linguística e Língua Portuguesa) pela PUC-Rio (2000). Doutorado em Linguística pela UNICAMP (2006) e Pós-Doutorado na área de Português como Segunda Língua pela PUC-Rio (2011). Professor do Dep. de Língua Portuguesa e Filologia (LIPO) do Instituto de Letras da UERJ e do Programa de Pós-graduação em Letras da UERJ. Coordenador do Núcleo de Pesquisa e Ensino de Português como Língua Estrangeira/Segunda Língua (NUPPLES - dgp.cnpq.br/dgp/espelhogrupo/3142754199429369). Orcid ID: https://orcid.org/0000-0003-3714-1176. E-mail:
} alexandredoamaralribeiro@gmail.com 
esse cenário e, de forma mais específica, sobre professores que atuam com alunos surdos em situação de inclusão e quais relações estabelecem com o ensino de LPE para alunos surdos. Analisam-se, em uma perspectiva exploratório descritiva, narrativas de professores que atuam com alunos surdos nos anos iniciais de redes municipais da Baixada Fluminense. As categorias de análise se organizam a partir de dois eixos: informações sobre a aprendizagem escolar de surdos, e as articulações entre crenças e percepções sobre a aprendizagem de alunos surdos. Utilizam-se os princípios da pesquisa-ação, analisando narrativas de professores. As narrativas apresentam elementos que evidenciam as percepções dos professores sobre o ensino e a aprendizagem de alunos surdos em contexto de inclusão, apontando para o papel que a escola exerce no aprendizado do aluno surdo e as questões que envolvem os saberes e os fazeres pedagógicos dentro do contexto escolar.

Palavras-chave: Alunos surdos. Ensino de língua portuguesa escrita. Relações.

\title{
CHALLENGES IN THE BILINGUAL EDUCATION OF THE DEAF: the relations that teachers establish with teaching of written Portuguese language for the deaf
}

\begin{abstract}
Only in recent times have actions been proposed aimed at promoting changes in social relations with people with disabilities in an inclusive perspective. Concerning the deafness and the deaf people, from a historical point of view, perceptions move from the concept of deafness as a disease to the idea of difference, oscillating between the characterization of deafness as a restriction and the recognition of the deaf people and his educability and potentialities. The search for methodologies, strategies and educational assistance, aimed specifically at the deaf students, exemplifies the advances of this discussion. In the school context it is relevant to understand the teachers' view of the deafs, their participation in school activities and the specific forms of teaching. This article reflects on this scenario and, more specifically, on teachers who work with deaf students in inclusion situations and which relattions stablish with teaching of written Portuguese language for the deaf. In an exploratory descriptive perspective, narratives of teachers who work with deaf students in the initial years of municipal schools from Baixada Fluminense are analyzed. The categories of analysis are organized from two axes: information about the deaf school learning, and the articulation between beliefs and perceptions about the learning of deaf students. We use the principles of action research, analyzing teachers' narratives. The narratives present elements that evidence teachers' perceptions about the teaching and learning of deaf students in the context of inclusion, pointing to the role that the school plays in the learning of the deaf student and the questions that involve the knowledge and the pedagogical tasks within the school context.
\end{abstract}

Keywords: Deaf students. Teaching of writting portuguese language. Relations.

\section{DESAFÍOS EN LA EDUCACIÓN BILINGÜES PARA SORDOS: relaciones que los maestros establecen con la enseñanza del portugués escrito para sordos}

\section{RESUMEN}

Revista Exitus, Santarém/PA, Vol. 10, p. 1-26, e020004, 2020. 
En los últimos tiempos, se han propuesto acciones destinadas a promover cambios en las relaciones sociales con personas con discapacidad desde una perspectiva inclusiva. Con respecto a la sordera las percepciones cambian de la concepción como una enfermedad a la idea de la diferencia, oscilando entre su caracterización como una restricción y el reconocimiento de la educabilidad y las potencialidades del sujeto sordo. La búsqueda de estrategias y servicios educativos, específicamente dirigidos a los sordos, ejemplifican los avances de esta discusión. En el contexto escolar, es relevante comprender la opinión que los maestros tienen sobre los sordos, su participación en las actividades escolares y las formas específicas de enseñanza. Este artículo reflexiona sobre este escenario, específicamente, sobre los maestros que trabajan con estudiantes sordos en una situación inclusiva. Desde una perspectiva exploratoria descriptiva, se analizan narraciones de los docentes que trabajan con estudiantes sordos en los primeros años de la escuela. Las categorías de análisis se organizan en dos ejes: información sobre el aprendizaje escolar y las articulaciones entre creencias y percepciones sobre el aprendizaje de los estudiantes sordos. Se utilizan los principios de la investigación en acción, analizando las narrativas de los maestros. Las narrativas presentan elementos que resaltan las percepciones de los maestros sobre la enseñanza y el aprendizaje de los estudiantes sordos, señalando el papel que juega la escuela en el aprendizaje de los estudiantes sordos y los problemas que involucran el conocimiento y las prácticas pedagógicas dentro de la escuela.

Palabras clave: Estudiantes sordos. Enseñanza de la lengua portuguesa escrita. Educación bilingüe.

\section{INTRODUÇÃO}

A dimensão inclusiva da sociedade vem ganhando força sob diferentes formas (JANNUZZI, 2004; CARMO, 1991). Considerando o contexto educacional, em 1990 é proclamada a Declaração Mundial sobre Educação para Todos, com vistas a promover a equidade no acesso à educação, assinalando que as necessidades básicas de aprendizagem das pessoas com deficiências requerem atenção especial (UNESCO, 1990). Em 1994, a Declaração de Salamanca, ao tratar Sobre Princípios, Políticas e Práticas na Área das Necessidades Educativas Especiais, estabelece que a educação de pessoas com deficiências integre os sistemas educacionais dos países participantes, reafirmando o compromisso com a Educação para Todos (UNESCO, 1994). Em 2007, a Convenção Internacional sobre os Direitos das Pessoas com Deficiência reafirmou os propósitos de promover, assegurar e proteger o "exercício pleno e equitativo de todos os direitos humanos e liberdades fundamentais por todas as pessoas com deficiência e promover o respeito pela sua dignidade inerente" (BRASIL, 2009).

Dentro desse contexto, mudanças nas instituições educacionais se fazem necessárias a fim de refletir o posicionamento inclusivo da sociedade 
contemporânea. Nesse sentido, considerando-se as indicações de Nóvoa (1995), torna-se necessária uma formação que contribua com a busca de alternativas para questões concretas da prática docente cotidiana. A escola aberta a todos é vocação da própria instituição e precisa se preocupar em compartilhar os saberes com todos que a frequentam (MEIRIEU, 2005).

No contexto brasileiro, as questões relacionadas à inclusão, especificamente no ambiente educacional, avançam paulatinamente. Uma das principais modificações observadas (e que vale ser destacada) é a Lei de Diretrizes e Bases para a Educação Nacional - Lei no 9.394 (BRASIL, 1996), que trata dessa questão quando conceitua a Educação Especial como a modalidade de educação escolar voltada para os alunos com necessidades educacionais especiais, afirmando a presença, preferencialmente, desses alunos na escola regular. A partir da determinação de que cabe à escola incluir, tornam-se necessárias medidas destinadas à formação de professores. Em boa parte das situações, esse conjunto de elementos formativos a respeito das diferenças e dos diferentes é oferecido como apêndice da formação, em disciplinas eletivas (MARTINS et al., 2006).

Especialmente em relação aos surdos, a legislação (BRASIL, 2002; 2005) pretende promover mudanças nas relações da sociedade com esses sujeitos. No âmbito da educação desses sujeitos, o Decreto $n^{\circ} 5.626$ (BRASIL, 2005) aponta para a necessidade de uma educação bilíngue para surdos, com a Libras como primeira língua (LI) e a língua portuguesa, na modalidade escrita, como segunda língua (L2). No contexto da formação dos profissionais para atuação com alunos surdos, a mesma legislação indica a inclusão de componente curricular que trate do ensino de Língua Portuguesa Escrita (LPE) para alunos surdos, determinando:

Art. 13. O ensino da modalidade escrita da Língua Portuguesa, como segunda língua para pessoas surdas, deve ser incluído como disciplina curricular nos cursos de formação de professores para a educação infantil e para os anos iniciais do ensino fundamental, de 
nível médio e superior, bem como nos cursos de licenciatura em Letras com habilitação em Língua Portuguesa.

Parágrafo único. O tema sobre a modalidade escrita da língua portuguesa para surdos deve ser incluído como conteúdo nos cursos de Fonoaudiologia (BRASIL, 2005, Art. 13).

A inclusão dos conhecimentos sobre ensino de LPE como L2 na formação de professores, indicado no Decreto $n^{\circ} 5.626$, representa um esforço em discutir as questões relacionadas às concepções de ensino de L2 para surdos. Isso permite inferir que a inclusão, não apenas dessa disciplina, mas como a de Libras (BRASIL, 2005), contribui para a promoção de reflexões acerca da organização do ensino de LPE para alunos surdos na educação básica, principalmente nas séries iniciais do ensino fundamental. Questões essas nem sempre familiares ao professor em formação (SANTANA, 2007).

Outras questões têm influência direta e indireta nas relações que estes professores estabelecem com o ensino de LPE para surdos, com os alunos surdos e com eles mesmos. Também refletem na organização didática desse ensino por parte dos professores. A atuação docente é constituída de várias facetas que exercem papéis diferentes na constituição do professor. Buscase, aqui, mostrar como a relação que os professores apresentam com o ensino de LPE para alunos surdos e com os alunos surdos se estabelecem, a partir de narrativas de professores sobre esse público-alvo nas séries iniciais do ensino fundamental na Baixada Fluminense.

\section{OS PROFESSORES, O ENSINO DE LPE E OS ALUNOS SURDOS}

A situação linguística dos sujeitos surdos brasileiros precisa ser levada em consideração. As crianças surdas são, em sua maioria, filhas de pais ouvintes que nunca tiveram contato com a língua de sinais (MOURA, 2013). Por este motivo, ressalta-se que a Libras não pode ser apontada como "língua materna dos surdos brasileiros", pelo menos não no sentido de como aquela que se aprende com a família (COX, 2004). Considerar a Libras como L1 também não é inteiramente possível no sentido de "ordem de aquisição", pois, como apontado por Quadros (1997), a maioria dos alunos surdos terá contato com a Libras apenas no ambiente escolar ou em outros espaços na relação com pares surdos usuários dessa língua. 
A partir da perspectiva do bilinguismo para educação de surdos, é que se aponta a necessidade do ensino da língua portuguesa como L2 para alunos surdos (SKLIAR, 1998). Com a obrigatoriedade legal de uso da LPE por esses sujeitos (BRASIL, 2002), há uma demanda crescente de estratégias para esse ensino.

Essa obrigatoriedade legislativa provoca mudanças de atitudes e práticas desenvolvidas pelas instituições da sociedade, entre elas a escola, que talvez seja a que sofre impacto mais aparente dessas "novas" demandas sociais. Referente à inclusão escolar de alunos surdos, é relevante compreender a visão que os professores têm da criança surda, da sua participação nas atividades escolares e as formas específicas de ensino (LACERDA; LODI, 2014), assim como a relação com os demais atores do contexto escolar (BETTI; CAMPOS, 2016).

Os professores estabelecem relações de diversas ordens durante sua atuação no processo de ensino-aprendizagem. Uma das formas de compreender essas relações (e será abordada aqui) é a proposta por Charlot (2000), que se refere as relações que o professor estabelece com o saber, e são definidas como: relações com o mundo, consigo mesmo e com o outro, onde cada professor as estabelece de uma forma particular.

A partir dessa perspectiva, a relação com o saber é definida como "uma forma da relação com o mundo" (CHARLOT, 2000, p.77). Por se dar de forma diferente para cada um, é permeada e movida pelos desejos dos sujeitos, com histórias particulares que constituem a singularidade desses e as suas formas de dar sentido ao mundo que se relacionam. No caso dos professores que atuam com ensino de LPE para alunos surdos, pode-se entender a relação com o mundo como uma relação com um local onde os alunos e esses professores estão presentes, assim como saberes escolares e os demais agentes presentes nesse ambiente. Entre os saberes que serão mobilizados estão os que foram abordados na sua formação, como as noções teóricas a respeito da LPE, uma vez que: 
[...] de alguma forma, o professor que teve acesso, durante sua formação acadêmica, a informações teóricas sobre essas noções, acaba por atualizá-las ou mobilizá-las, em sala de aula [...]. No entanto, em sua atuação efetiva, o professor necessita mobilizar outros conhecimentos como aqueles previstos pelo livro didático que esteja sendo utilizado na escola. O resultado é que, em sua prática, o professor produz adaptações, e a noção teórica (como a de texto), tal como formulada inicialmente pela Linguística, é transformada ou (re)construída, juntamente com outros saberes ou conteúdos, para atender às necessidades da situação de sala de aula. Assim, o professor constrói, em sua prática, conceitos, que já não são mais exatamente aqueles previstos pela teoria linguística e/ou por obras de divulgação, mas são objetos próprios da situação de ensino (RAFAEL, 2001, p. 158).

A constituição desses saberes e as relações que os professores estabelecem com eles são advindas também da sua própria atuação. Isso está em função da pluralidade dos saberes que compõem a prática docente, que são originados não apenas na formação desses professores, mas também a partir dos currículos e das experiências a que estes estão expostos (TARDIF, 2002).

A relação estabelecida com o outro e com a diferença, também constitutiva dos saberes do professor, precisam ser construídas a partir de pressupostos que favoreçam a atuação docente a partir da perspectiva inclusiva. Esses "saberes inclusivos" precisam estar presentes na formação dos professores que atuarão com ensino de LPE para surdos. Nesse sentido:

[...] é importante assinalar que é em torno da definição do quanto um indivíduo poderia ser educável e na formalização de modelos institucionais destinados a esse público que localizamos referenciais ainda ressoantes sobre o acesso deles à escolarização (RAHME, MRECH, 2008, p. 27).

A busca pela compreensão dos sujeitos surdos a partir de uma visão propositiva é algo que deve integrar as discussões e reflexões acerca desses sujeitos no processo de formação de professores. Essa é uma das abordagens que pode favorecer a mudança na dimensão social das relações dos professores com os alunos surdos e com o ensino de LPE para esses sujeitos. Isso nos leva a observar essas questões de forma mais ampla, sendo necessário refletir sobre as políticas educacionais e suas formas de 
desenvolvimento, como também sobre a formação oferecida aos professores para enfrentar os desafios contemporâneos das salas de aula na educação básica (SILVA; ALMEIDA; GATTI, 2016).

Ainda a respeito, crenças e expectativas dos professores compõem os aspectos que podem afetar o desempenho acadêmico dos alunos. Essa questão da influência das expectativas dos professores em relação ao aluno e o (in)sucesso escolar já é recorrente desde a década de 1960, ganhando notoriedade com a publicação de "Pigmaleão4 na sala de aula" (ROSENTHAL; JACOBSON, 1968), em que foi defendida a tese de que as expectativas dos professores influenciam as realizações escolares dos alunos, assim como seu desenvolvimento intelectual.

Outros estudos foram realizados a fim de apontar a influência e a relação de causalidade entre a expectativa do professor e o desempenho escolar dos alunos. Alguns aspectos são observados para estabelecer essa relação de causalidade, constituindo um modelo da expectativa do professor (GOOD, 1981). Esse se apresenta da seguinte forma:

[...] o professor espera comportamento e realização específicos de determinados alunos; devido a essas expectativas diferenciadas, o professor se comporta de maneira diferente em relação a diferentes alunos; esse tratamento comunica ao aluno qual comportamento e desempenho o professor espera dele e afeta o comportamento, a motivação para o desempenho e os níveis de aspiração do aluno; esse tratamento é consistente no tempo e se os alunos não the opõem resistência ou não o modificam de qualquer modo, ele irá moldar o desempenho e o comportamento do aluno: os alunos em relação aos quais o professor tem grandes expectativas serão levados a bons desempenhos e os alunos em relação aos quais o professor tem pequenas expectativas irão apresentar um desempenho inferior; com o decorrer do tempo, os resultados escolares e o comportamento do aluno irão se adaptando cada vez mais ao comportamento originalmente esperado dele (GOOD, 1981 apud RASCHE, KUDE, 1986, p. 61).

Essa expectativa e a forma de apresentação dos seus comportamentos, conforme apresentado por Good (1981), também são

\footnotetext{
4 O "efeito Pigmalião" é usado para se referir ao efeito causado pelas expectativas que os docentes têm sobre o desempenho escolar satisfatório ou insasfatório dos discentes. Tal nomenclatura é proveniente de um mito grego, que pode ser compreendido melhor durante a leitura da obra de Rosenthal e Jacoboson (1968).
} 
encontradas quando da presença de alunos com alguma deficiência. Nesses casos, as expectativas estão relacionadas às características individuais desses alunos (PARIZZI, 2000). Dessa forma, quando se trata dos alunos surdos, a questão da expectativa se apresenta também como força que influencia o desempenho escolar desses alunos e implica delimitar a sua possibilidade de desenvolvimento e de aprendizagem (ARTROLLI, 1999).

A forma como os professores representam os alunos surdos determina o tipo de relação que estabelecem com esses sujeitos, o que constitui as crenças desses professores. Estas crenças são ideias e convicções a respeito de determinados temas ou sujeitos que se revelam, de forma consciente ou inconsciente, nas ações dos professores (RAYMOND; SANTOS, 1995). Isso têm influência no processo de ensino-aprendizagem, uma vez que mediam as decisões pedagógicas e as relações que os professores estabelecem com os alunos e com os saberes. Atuam como uma espécie de um filtro que leva o docente a interpretar, valorizar e reagir de diferentes formas no que diz respeito aos progressos e dificuldades dos alunos, podendo até mesmo induzir o desempenho real desses alunos, indo ao encontro das expectativas dos professores (PAJARES, 1992).

Assim, essas crenças podem criar barreiras à aprendizagem de surdos em classes regulares, pois influencia a postura do professor em relação ao aluno (ARTROLLI, 1999). A reflexão sobre essas crenças presentes na sociedade se apresenta como um dos desafios a ser abordado na formação de professores, conforme salientado por Rahme e Mrech (2008):

Lidar com essas diferentes realidades nos cursos de formação docente é um desafio que vem sendo colocado tanto nos processos de formação inicial quanto nos de formação continuada, sobretudo quando se parte do princípio de que na educação escolar o encontro com o outro é constituinte do exercício profissional. E o encontro com esse outro tem, no caso da pessoa com necessidades educacionais especiais, concepções previamente construídas que precisam ser consideradas e trabalhadas nos processos de formação, de modo a superar o mero conhecimento classificatório em direção à maior implicação do sujeito naquilo a que ele acede. Para tanto, não seria muito dizer que organização de curso, perfil profissional, currículo e metodologias são elementos fundamentais na formação de professores, desde que articulados por concepções 
teóricas que os tornem flexíveis diante das particularidades do cotidiano e suficientemente críticas para detectar as armadilhas da segregação que, como assinalamos, tendem a se tornar a cada dia mais discretas e manipuláveis em nossa sociedade (p. 37-38).

A preocupação em apresentar o contato com os sujeitos diferentes de uma forma que possibilite a mudança nas crenças é essencial. "Cuidar dos professores é fundamental ao se pensar em transformações educacionais com visão na construção de uma sociedade mais justa, mais equitativa" (GATTI, 2008, p. 42). Assim, pensando a partir de uma perspectiva inclusiva, o desejo de mudança nas relações que a sociedade estabelece com os sujeitos surdos deve motivar a busca por oportunizar aos professores uma formação que possibilite a esses a construção de crenças em relação aos surdos diferentes das que o entendem como incapaz ou limitado.

Possibilitar o contato com a questão do ensino para alunos com deficiência e da educação especial é um aspecto que precisa ser discutido a respeito dos currículos de formação de professores. Mesmo não sendo objeto deste artigo tratar de forma aprofundada os currículos para formação de professores, vale salientar que a discussão da deficiência e da inclusão durante a formação tem reflexo na atuação docente. "Mais do que ensinar, monitorar ou criticar, o que importa numa relação de aprendizagem são as crenças, os objetivos e as intenções que circulam por todos os participantes do processo" (COELHO, 2012, p. 133). Neste sentido, o professor precisa se reconhecer enquanto agente no processo de ensinoaprendizagem dos alunos, apresentando objetivos e intenções que favoreçam a efetivação desse processo para todos os alunos, dentre eles, os alunos surdos.

Dessa forma, se essas questões forem abordadas na formação, as expectativas dos professores podem ser voltadas para a possibilidade ou "educabilidade" dos alunos surdos, influenciando o seu posicionamento frente ao ensino de LPE para eles. Esse posicionamento é refletido por meio das relações que os professores estabelecem com eles mesmos, com o ensino de LPE para alunos surdos, e com os alunos surdos. A atuação 
docente desses professores pode ser organizada de forma que favoreça a efetivação do processo de ensino-aprendizagem desses alunos.

\section{OS PROFESSORES E ELES MESMOS}

O que se apresenta neste artigo resulta de estudo sobre as relações que professores atuantes na educação de surdos no primeiro segmento do ensino fundamental $\left(1^{\circ}\right.$ ao $5^{\circ}$ ano), em redes municipais de ensino da Baixada Fluminense, estabelecem com o ensino de LPE para surdos. Foram selecionados 14 professores que participaram de curso de extensão que tratava da temática do ensino de LPE para alunos surdos, promovido pelo Grupo de Pesquisa em Alfabetização, Letramento, Cultura e Sociedade (GEALCS), da Universidade do Estado do Rio de Janeiro - Faculdade de Educação da Baixada Fluminense. Como metodologia para o desenvolvimento do estudo, os encontros do curso de extensão foram tomados como grupos focais. Foram realizados um total de 15 encontros que ocorreram nas dependências da Faculdade de Educação da Baixada Fluminense, na maioria dos casos, com periodicidade quinzenal. De acordo com a indicação para condução de grupos focais (KITZINGER, 2000), os conteúdos foram planejados pelo GEALCS a partir de temáticas prédefinidas (Quadro 1) e ainda a partir das indicações dos encontros anteriores, com vistas a garantir a continuidade do processo.

Quadro 1 - Tópicos discutidos durante os encontros promovidos na realização desse estudo

\begin{tabular}{|c|c|c|}
\hline Encontro & Dimensão (Teórica ou Prática) & Tema ou atividade \\
\hline $1^{\circ}$ & Teórica & Concepções de letramento. \\
\hline $2^{\circ}$ & Teórica & Letramentos e seus conceitos. \\
\hline $3^{\circ}$ & Teórica & Letramentos múltiplos e multiletramentos. \\
\hline $4^{\circ}$ & Teórica & Língua, linguagem e surdez. \\
\hline $5^{\circ}$ & Teórica & $\begin{array}{l}\text { Conceitos de língua e abordagens de } \\
\text { ensino. }\end{array}$ \\
\hline $6^{\circ}$ & Teórica & Língua e ensino na educação de surdos. \\
\hline $7^{\circ}$ & Teórica e Prática & $\begin{array}{l}\text { Introdução à organização didática para } \\
\text { ensino de surdos. }\end{array}$ \\
\hline $8^{\circ}$ & Teórica e Prática & Planejamento e seus elementos. \\
\hline
\end{tabular}




\begin{tabular}{|l|l|l|}
$99^{\circ}$ & Teórica e Prática & $\begin{array}{l}\text { Levantamento de domínio de Língua } \\
\text { Portuguesa. }\end{array}$ \\
\hline $10^{\circ}$ & Prática & $\begin{array}{l}\text { Construção de planejamento orientado } \\
\text { por situação problema. }\end{array}$ \\
\hline $11^{\circ}$ & Prática & $\begin{array}{l}\text { Análise dos planejamentos de forma } \\
\text { coletiva, com indicações para aplicação. }\end{array}$ \\
\hline $12^{\circ}$ & Prática & $\begin{array}{l}\text { Discussão da aplicação dos } \\
\text { planejamentos, apontando melhorias } \\
\text { possíveis. }\end{array}$ \\
\hline $13^{\circ}$ & Prática & $\begin{array}{l}\text { Apresentação de aula experimental pelo } \\
\text { GEALCS, com discussão do planejamento } \\
\text { de forma coletiva. }\end{array}$ \\
\hline $14^{\circ}$ & Prática & $\begin{array}{l}\text { Apresentação de aula experimental pelo } \\
\text { GEALCS, com discussão do planejamento } \\
\text { de forma coletiva. }\end{array}$ \\
\hline $15^{\circ}$ & Prática & $\begin{array}{l}\text { Apresentação de aula experimental pelo } \\
\text { GEALCS, com discussão do planejamento } \\
\text { de forma coletiva. }\end{array}$ \\
\hline
\end{tabular}

Fonte: elaboração dos autores (2019).

Ressalta-se que as análises realizadas nesse estudo incidem sobre as narrativas dos professores atuantes no ensino de LPE para alunos surdos na Baixada Fluminense, registradas durante grupos focais e posteriormente transcritas para análise. Os aspectos atribuídos às escolas e aos alunos surdos servem como elementos complementares de análise, uma vez que não se teve acesso a esses outros sujeitos e espaços. Referente às perspectivas dos professores sobre sua condição de professor e sobre as relações estabelecidas entre língua(gem) e o ensino de LPE para surdos, estas se apresentam conforme descritas a seguir e podem ser dimensionadas conforme apresentado no Quadro a seguir.

Quadro 2 - Síntese das perspectivas dos professores sobre as relações que estabelecem entre língua(gem) e o ensino de LPE para surdos

\begin{tabular}{|c|c|}
\hline Desconhecimento & Conhecimento \\
\hline $\begin{array}{l}\text { - Não tem vivência com a diferença; } \\
\text { - Ensinar surdo é coisa de outro mundo; } \\
\text { - Não conhecem sobre a surdez; } \\
\text { - Não conhecem a cultura surda; }\end{array}$ & $\begin{array}{l}\text { - Funcionamento cognitivo do surdo é igual } \\
\text { do ouvinte; } \\
\text { - Não há tanta diferença na aprendizagem } \\
\text { do surdo em relação aos outros alunos; } \\
\text { - Libras nem sempre é a Língua Materna. }\end{array}$ \\
\hline Crenças restritivas & Crenças propositivas \\
\hline $\begin{array}{l}\text { - Não precisa aprender a língua } \\
\text { portuguesa; } \\
\text { - Libras é Língua Materna; } \\
\text { - Libras é o suficiente para o surdo. }\end{array}$ & $\begin{array}{l}\text { - Libras não é Língua Materna para maioria } \\
\text { dos surdos; } \\
\text { - Ensino de LPE como L2; } \\
\text { - Uso da língua portuguesa para aprender a } \\
\text { língua portuguesa. }\end{array}$ \\
\hline Inabilidades & Alternativas \\
\hline - Gramática é difícil; & - Visão metalinguística do ensino de LPE \\
\hline
\end{tabular}


- Não fazer uso da língua no ensino;

- Vocabulário limitado;

- Estratégias tradicionais de ensino. para surdos;

- Estratégias práticas;

- Motivação para a aprendizagem;

- Ensino dinâmico e contextualizado:

- Atividades que chamem atenção do aluno surdo.

Fonte: elaboração dos autores (2019).

Do ponto de vista das percepções dos professores sobre eles mesmos, essas oscilam entre uma visão propositiva em relação ao ensino de LPE para alunos surdos e outra restritiva e, em alguns casos, impeditiva. Pode-se inferir que a oscilação se reflete na presença tímida ou bem marcada de princípios, os quais orientam a ação docente desses professores. Isso fica mais evidente quando se observa o binômio inabilidades e alternativas didático-pedagógicas, que podem ter principal influências das crenças e conhecimentos apresentados nas narrativas. A ação didático-pedagógica parece transitar entre inabilidade e alternativa em função dos conhecimentos ou desconhecimento, que, por sua vez, tem influência nas crenças propositivas ou restritivas. Aparentemente, é uma relação encadeada entre esses elementos, podendo se apresentar de forma restritiva para o ensino ou como oportunidade de perceber as possibilidades no contexto do ensino de LPE para alunos surdos. Essa organização de ideias expressas nas narrativas será detalhada a seguir a partir de um agrupamento em dois eixos: o primeiro na ordem das limitações e o segundo na ordem das possibilidades.

Nas narrativas dos professores, é recorrente os elementos que apontam para o desconhecimento dos conceitos que envolvem a surdez e os sujeitos surdos entre os que atuam com ensino de LPE para alunos surdos. Isso pode ser observado na Figura 1.

Figura 1 - Síntese das perspectivas dos professores no eixo das informações sobre a os surdos 


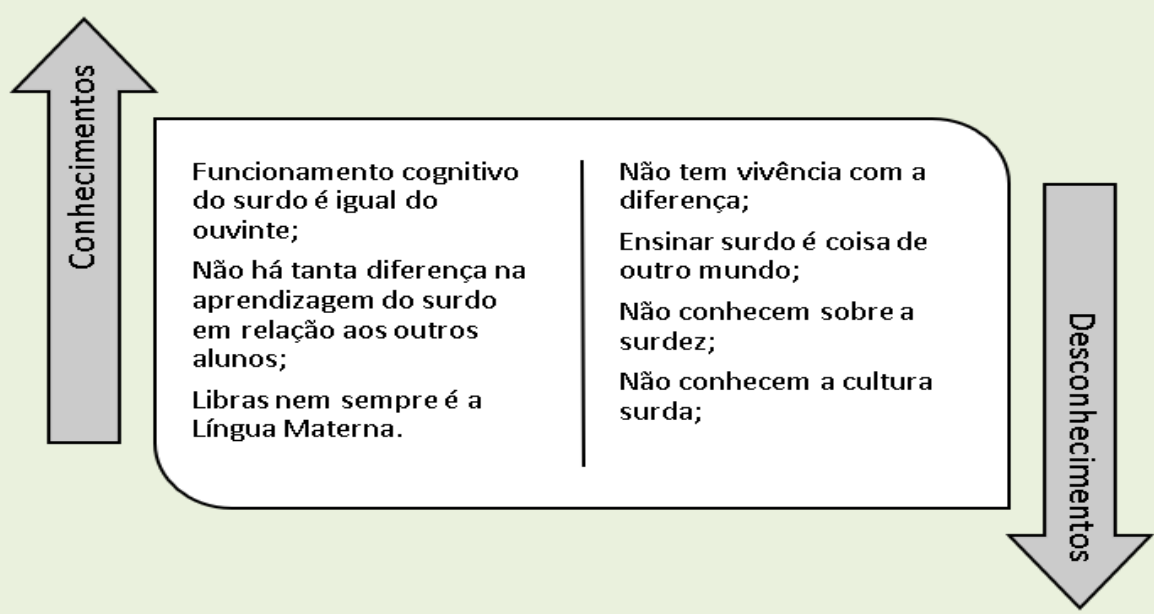

Fonte: elaboração dos autores (2019).

As narrativas dos professores apontam para uma exaltação das dificuldades de aprendizagem, atribuindo ao sujeito surdo essas dificuldades apenas pela sua condição de surdo. Parece ser componente dessas concepções a ideia de que por ser surdo automaticamente ele não aprende português ou se aprende tem grandes dificuldades e complicações para o entendimento da LPE. Isso pode ser um reflexo também das crenças e do desconhecimento, já que, como apontado por Coelho (2005), os professores em serviço acreditam que os alunos sejam fracos e por isso só devem ensinar coisas fáceis e básicas.

Esses desconhecimentos apresentados pelos professores podem ser resultado de uma formação inicial que não proporcionou reflexões acerca do surdo e da surdez, gerando nesses professores atitudes como: insegurança, desconfiança e receio frente às mudanças (ESTEVE, 1995). A entrada de alunos surdos no sistema de ensino regular provocou essa aproximação dos professores com esses sujeitos. As narrativas refletem as dificuldades, dilemas e uma sensação de desamparo quando os professores se deparam com uma situação que foge do habitual, colocando-os em contato direto com o diferente (OLIVEIRA, 2009).

Durante os encontros, os professores tiveram contato com conceitos e discussões que objetivaram ampliar o conhecimento a respeito do surdo e da surdez. O contato com essas informações e a construção de conhecimentos a respeito do surdo e da surdez possibilitaram aos professores uma perspectiva diferente. Ainda é ressaltado que a saída do senso comum 
para um contexto em que são estudadas essas questões teve grande impacto na forma como o surdo é percebido pelos professores. O conhecimento de que a Libras não se constitui como língua materna para a maioria dos surdos possibilita mudança na forma de ver o surdo e de perceber as línguas dentro desse contexto.

A mudança apontada aqui não ocorre de forma espontânea. É preciso que o professor tenha contato com os fundamentos epistemológicos, os quais podem guiar a construção das suas práticas de ensino de LPE para alunos surdos. É fundamental cada professor refletir, em cada situação, a respeito de quem é o aluno surdo, das suas diferenças e sobre quais bases ideológicas as suas concepções de ensino estão pautadas, considerando sempre o aluno surdo como um ser humano na sua plenitude (DORZIAT, 2004).

As narrativas trazem marcas das crenças dos professores sobre o ensino de LPE para surdos. Essas crenças podem estar associadas aos desconhecimentos apresentados anteriormente. Observa-se essa articulação entre as crenças e seus possíveis efeitos na Figura 2.

Figura 2 - Síntese das perspectivas dos professores no eixo das crenças e percepções 

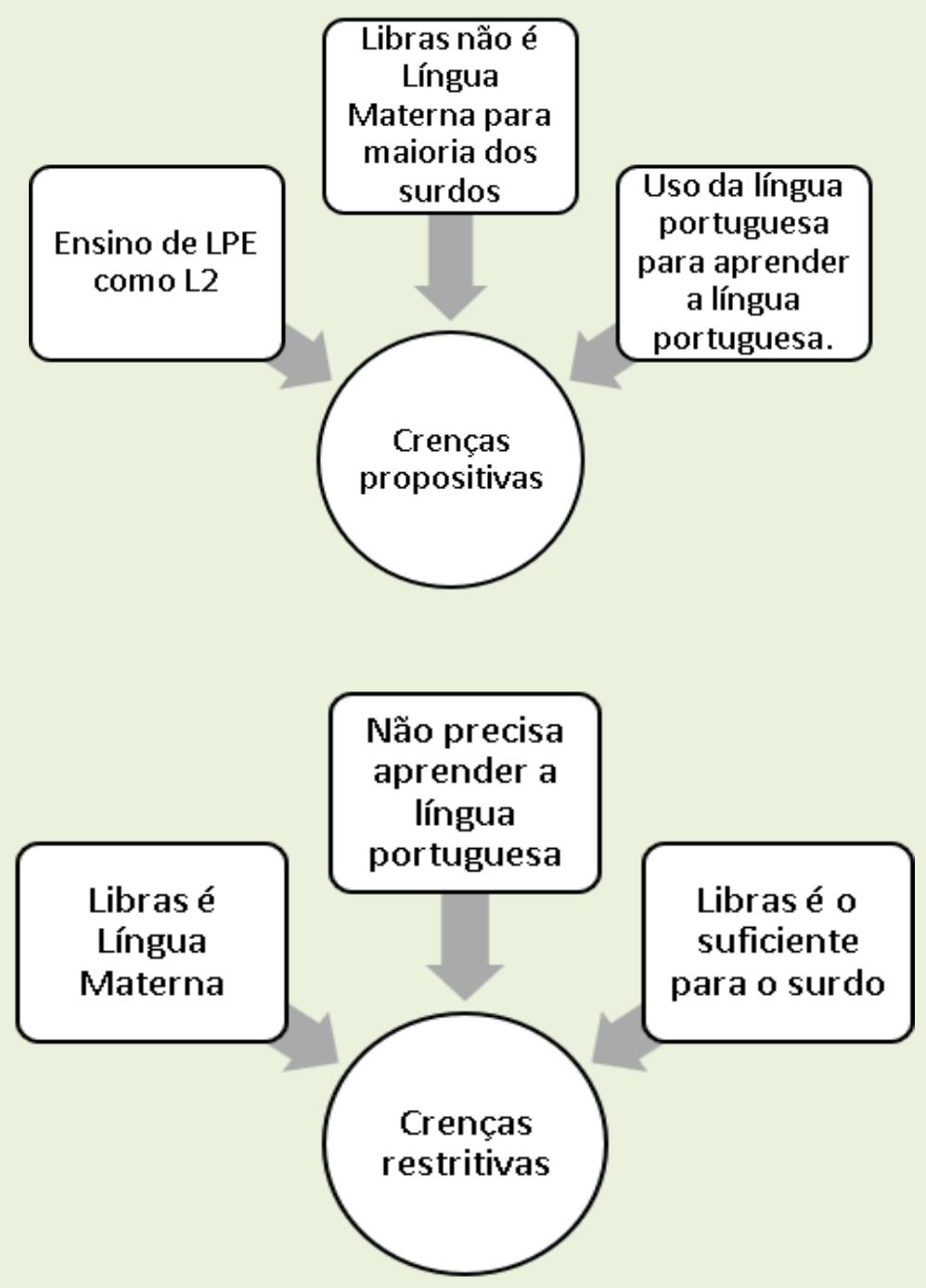

Fonte: elaboração dos autores (2019).

Observam-se, essencialmente, duas crenças que dizem respeito à necessidade ou não da LPE e ao entendimento da Libras como língua materna. Se analisadas a partir de uma concepção sociológica, essas crenças podem ser entendidas como uma "causa-regente". A ação dos sujeitos e da sociedade tem uma consequência no aspecto social, que não é necessariamente realizada de forma consciente e é possível que os sujeitos não tenham a percepção de que essas crenças existem e como foram construídas (BOUDON; BOURRICAUD, 1993). Elas têm influência direta na ação dos sujeitos e em como estes se relacionam com os objetos centrais dessas crenças. 
Essas crenças podem influenciar a forma como os professores se relacionam com ensino de LPE para surdos, uma vez que admitir que o surdo não tem necessidade de aprender a LPE, por ter uma outra língua (Libras), pode desenvolver no professor "uma disposição para a ação; e pode transformar-se em regras de comportamento, devido ao alto grau de probabilidade e estabilidade. São consideradas princípios filosóficos que orientam a prática do professor" (BANDEIRA, 2003, p. 65).

A outra crença refere-se ao entendimento da Libras como língua materna dos surdos. Isso pode interferir na atuação de professores que não possuem domínio de Libras, e, como tal, se colocam em posição de impedimento para o ensino da LPE para surdos. Acreditar nisso pode comprometer tanto o trabalho do professor que não tem domínio da Libras quanto o provável aprendizado do aluno surdo que não possui a Língua de Sinais estruturada e nem a utiliza como língua materna.

As discussões realizadas no conjunto de grupos focais resultaram em possíveis modificações nos modos de perceber a necessidade de uso da língua portuguesa para aprender e ensinar a modalidade escrita dessa língua para alunos surdos. Admite-se, portanto, a possibilidade de aprendizado da modalidade escrita da língua portuguesa por sujeitos surdos. É apontada também a crença de que é preciso que esse ensino seja realizado como uma $L 2$, assim como os ouvintes o fazem quando aprendem Libras como L2. Acrescenta-se ainda a mudança de crença em relação aos surdos e à Libras como língua materna. Na maioria dos casos, a Libras não se apresenta como língua materna para esses sujeitos.

Essas crenças passam a ser reconstruídas a partir do contato com novas informações e a apreensão de novos conhecimentos por parte dos professores. Elas constituem "um acervo vivo de verdades individuais ou coletivas, na maioria das vezes implícitas, (re)construídas ativamente nas experiências, que guiam a ação do indivíduo e podem influenciar a crença de outros que estejam ou não inseridos na sala de aula" (SILVA, 2005, p. 78). Dessa forma, o contato e as experiências durante os encontros promovidos por esse estudo possivelmente possibilitaram a reconstrução dessas crenças 
e isso pode influenciar na ação pedagógica para ao ensino de LPE para alunos surdos.

Os aspectos apontados anteriormente (desconhecimento do surdo e da surdez e crenças a respeito do sujeito surdo) parecem ter influência direta na inabilidade didático-pedagógica dos professores. Não ter conhecimento sobre o sujeito surdo, bem como as crenças de que a Libras é a língua materna de todos os surdos e a não necessidade de aprendizado da LPE por esses alunos, tudo isso compromete as ações dos professores. Pode-se observar essa relação na Figura 3.

Figura 3 - Síntese das perspectivas dos professores no eixo das possibilidades de organização didático-pedagógica

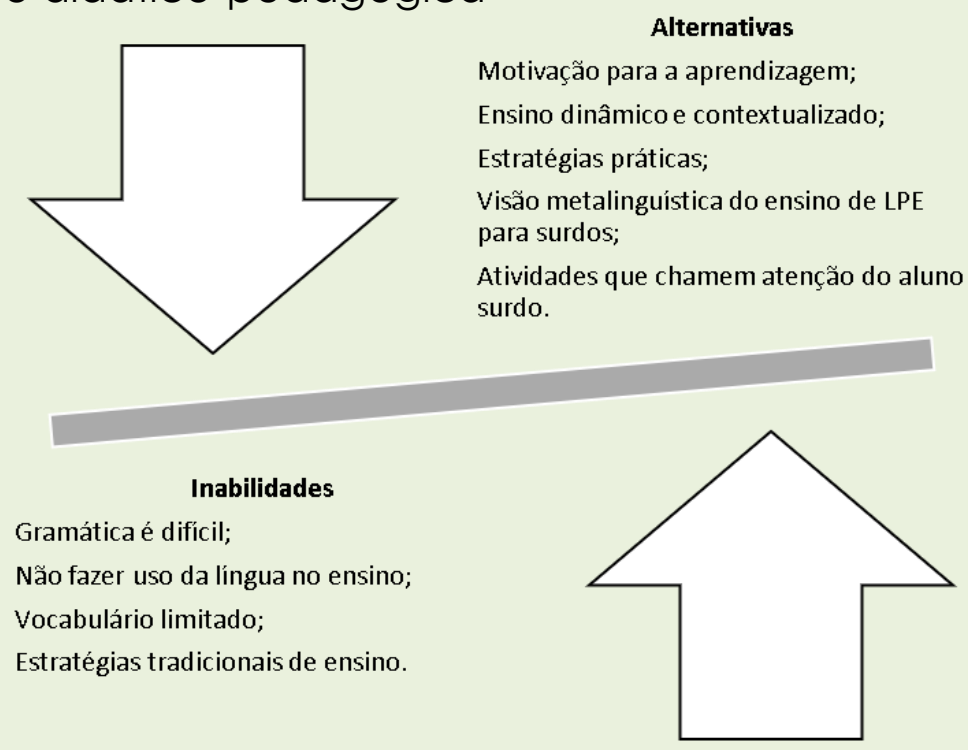

Fonte: elaboração dos autores (2019).

Os professores apontam para abordagens do ensino de LPE para surdos que são desaprovadas por eles mesmos. Os professores se colocam apenas como espectadores das ações de ensino e criticam ações mais tradicionais ou com foco limitado à gramática e ao desenvolvimento de vocabulário. Isso se reflete como uma inabilidade para organização do ensino de forma a favorecer a aprendizagem dos alunos surdos, referente à LPE.

São apontadas dificuldades para a ação pedagógica que ressaltam as influências das crenças e dos desconhecimentos. Observa-se isso quando o professor aponta que para o surdo é difícil aprender pois não tem o 
português de forma automática. Tal fato parece refletir a crença de que todos os surdos possuem a Libras como língua materna e, portanto, automática.

A concepção da Libras como língua materna ou automática para o surdo advém de uma ideia de que a língua natural dos surdos é a língua de sinais. No caso dos surdos brasileiros, na maioria das vezes, isso não ocorre. A maioria das crianças surdas está em famílias com responsáveis ouvintes e, dessa forma, não tem contato com a Libras desde o nascimento. Como não há esse contato, a Libras não se constitui como língua materna do surdo e, para que isso ocorra, seria preciso o convívio e "interações com outros surdos usuários da Libras ou pessoas ouvintes fluentes nesta língua" (DAMILELLl; CLASEN, 2012, p. 157).

A partir das mudanças em relação aos (des)conhecimentos sobre o surdo e a surdez, bem como as crenças a respeito do sujeito surdo identificadas pelos próprios professores, novos olhares e alternativas para a atuação didático-pedagógica são construídos. Indicam mudanças da visão de impossibilidade para a de possibilidade.

Os professores passam a perceber as alternativas possiveis para sua ação didático-pedagógica, ressaltando a necessidade de ter uma visão metalinguística em relação à $L P E$, de modo a promover a aprendizagem dos alunos surdos. Apontam também para uma mudança na percepção do ensino de LPE para surdos, saindo da visão de impossibilidade para a de possibilidade. Com isso, começam a ter contato mais amplo com estratégias e discussões sobre a temática.

É indicada ainda a questão da motivação, já que, para a aprendizagem, ela é decisiva para o aluno surdo. É preciso que os alunos surdos construam sentidos e significados propositivos sobre a aprendizagem da LPE. Nessa perspectiva, o professor desempenha papel fundamental. Destaca-se também a questão de mudança na seleção de estratégias didático-pedagógicas, saindo de uma abordagem estática para uma mais dinâmica, como escolha de textos contextualizados, atividades que estimulem o uso da língua e chamem a atenção dos alunos surdos. Ratifica- 
se a importância da reflexão e aprofundamento de conhecimentos para o professor.

\section{RELAÇÕES ESTABELECIDAS PELOS PROFESSORES ENTRE LÍNGUA(GEM) E O ENSINO DE LPE PARA SURDOS}

Ao discutir essas relações, a partir das perspectivas dos professores sobre sua condição de professor de alunos surdos, na ordem das limitações, chama atenção os seguintes aspectos: os professores ainda apresentam uma visão equivocada sobre a possibilidade e a necessidade de aprendizagem da LPE para surdos; compreendem a Libras como língua materna dos sujeitos surdos; e apresentam dificuldades de organizar atividades que favoreçam a aprendizagem da gramática e a ampliação de vocabulários dos alunos surdos. Na ordem das possibilidades, destaca-se: os professores compreendem a habilidade cognitiva da linguagem nos surdos não tendo comprometimento em virtude da surdez; entendem que a Libras, na maioria dos casos, não se constitui como língua materna para os surdos; e observam a necessidade de ensino de LPE para alunos surdos, a partir do entendimento de essa se constituir como L2 deles.

Ainda nas relações dos professores entre língua(gem) e o ensino de LPE para surdos, na perspectiva desses professores, salienta-se, na ordem das limitações, os seguintes aspectos: exaltam as dificuldades de aprendizagem dos alunos surdos, atribuindo isso apenas ao fato do aluno ser surdo; e se restringem ao ensino e organização didática na superficialidade da língua. $\mathrm{Na}$ ordem das possibilidades, chama atenção o fato de acreditarem que o surdo tem possiblidade de aprender, embora não da mesma forma de um aluno ouvinte.

A esse respeito, depreende-se das narrativas de professores que atuam no ensino de LPE para alunos surdos algumas indicações de como alguns referentes da ação docente se apresentam. Destacam-se, aqui, questões relacionadas: à compreensão dos processos de aprendizagem dos alunos surdos, expressa na ênfase do reconhecimento das dificuldades gerais e específicas da aprendizagem escolar desses alunos; ao conhecimento dos 
fatores sociais e psicológicos que envolvem os alunos surdos; e ao domínio de diferentes meios e alternativas práticas para a proposição de processos de intervenção adequados. Ainda se aponta que, na maioria das vezes, toma-se a deficiência pelo sujeito.

Outro ponto de destaque é o domínio da LPE e seu ensino para alunos surdos. Pode-se relacionar isso diretamente a oportunidades de atualização/formação continuada adequadas. Essa atualização/formação contribuiria para a adoção de novas ferramentas e abordagens pedagógicas. Acrescenta-se a capacidade de pensar pedagogicamente a respeito dos conteúdos ensinados, pois, quando ela é frágil, acarreta pouca clareza na definição dos objetivos e conteúdos de aprendizagem e planejamento das atividades de ensino a partir deles.

\section{CONSIDERAÇÕES (NÃO) FINAIS}

Os resultados apresentados permitem indicar que as perspectivas desses professores oscilam entre as limitações e as possibilidades. A ação didático-pedagógica parece transitar entre inabilidade e alternativa em função dos conhecimentos ou desconhecimento, que, por sua vez, tem influência nas crenças propositivas ou restritivas, sendo uma relação encadeada entre esses elementos. Esses aspectos permitem perceber que o olhar do professor sobre o aluno surdo ainda é transversalizado por equívocos, os quais vão desde o desconhecimento teórico sobre o surdo e a surdez até a presença de traços de permanência de crenças e expectativas anteriores à ação docente, parte da constituição do sujeito professor. Observou-se que essas expectativas e crenças, presentes nas narrativas dos professores, podem influenciar na sua atuação a partir das inabilidades ou das alternativas didático-pedagógicas. Isso pode ser indicado como um dos princípios norteadores da ação docente dos professores que atuam com ensino de LPE para alunos surdos.

A respeito dos desafios para formação e atuação docente com o ensino de LPE para alunos surdos, é questão principal: o contato com a temática da inclusão durante a formação inicial e, a partir de uma 
abordagem do respeito às diferenças, a busca de alternativas para efetivação do processo de ensino-aprendizagem. Esse contato pode contribuir para a diminuição dos desafios e a reflexão para organização do ensino, partindo de conceitos que consideram as pessoas a partir das suas possibilidades e não das dificuldades ou impedimentos. Embora isso seja indicado, observou-se entre os professores uma escassez de contato com essas temáticas, o que se reflete em crenças e preconcepções a respeito do aluno surdo e marca sobremaneira a forma como esses professores pensam e organizam experiências para aprendizagem de LPE. Ainda há de se destacar que as questões dos conteúdos tratados na formação não incluem o ensino de LPE como uma língua não materna e muitas vezes não abordam questões dos conteúdos da língua portuguesa. Isso parece comprometer o domínio tido pelos professores a respeito dos conteúdos da LPE e, consequentemente, também afeta a forma como atuam frente à necessidade de ensinar LPE para alunos surdos.

A presença das discussões no contexto escolar e na formação de professores, a respeito dos letramentos ${ }^{5}$, traz atenção para como essa temática é compreendida. Conhecer os conceitos e as formas de tratar essa questão permitiu identificar, nas narrativas dos professores que atuam no ensino de LPE para alunos surdos, como esses a abordam. Há, nos discursos de profissionais que atuam com alunos surdos, a apropriação da abordagem dos multiletramentos para pensar as experiências de ensinoaprendizagem dos alunos surdos. Ao tentar compreender os conceitos que integram a abordagem dos letramentos múltiplos, pode-se observar que essa "apropriação" pela área da educação de surdos parece ser aligeirada e com inconsistências teóricas. Pode-se observar isso pela ausência, nas narrativas dos professores participantes da pesquisa, de formas como a abordagem dos multiletramentos, a qual poderia estar presente em suas práticas pedagógicas. Ressalta-se que a questão basilar dos letramentos

\footnotetext{
${ }^{5}$ A questão dos letramentos perpassa por todos os estudos realizados pelo GEALCS e, ainda, que não componham os resultados apresentados aqui, fazem parte de um quadro mais amplo a respeito do ensino de LPE para surdos no contexto pesquisado durante a realização deste estudo.
} 
também não é apontada com uma apropriação que vá de acordo com os pressupostos teóricos apresentados nos estudos que tratam dessa temática.

Assim, são questões principais: o contato com a temática da inclusão durante a formação inicial e, a partir do respeito às diferenças, a busca de alternativas para efetivação do processo de ensino-aprendizagem; e para além desse contato uma revisão dos conteúdos da formação, proporcionando o cumprimento do Art. 13 do Decreto n 5.626 (BRASIL, 2005). Contudo, diante do observado, não parece ser elemento constituinte da formação inicial desses professores. Ainda nessa questão, o Art. 13 do Decreto $n^{\circ} 5.626$ (BRASIL, 2005) já indica a obrigatoriedade de se incluir na formação dos professores conteúdos voltados para o ensino de LPE para surdos, algo que não é incluído nos currículos de formação de professores para séries iniciais. Esses professores atuam na fase de alfabetização desses alunos e o domínio dos conteúdos foi apresentado nas narrativas como princípio norteador da sua prática pedagógica. Sem a formação necessária, o ensino exitoso da LPE para alunos surdos não se concretiza. Retomando especificamente a questão do contato, esse pode contribuir para a diminuição dos desafios e a reflexão para organização do ensino, partindo de conceitos que consideram as pessoas a partir das suas possibilidades e não das dificuldades ou impedimentos. Isso parece comprometer o domínio que os professores têm a respeito dos conteúdos da LPE e, consequentemente, também afetam a forma como organizam o ensino de LPE para alunos surdos.

Outra reflexão a respeito da formação inicial e continuada, parece também fazer parte do cotidiano dos professores participantes desse estudo, haja vista a exaltação, presente nas narrativas desses professores, da necessidade de utilizar formas mais efetivas de planejamento e organização do ensino de LPE para alunos surdos.

O desenvolvimento das habilidades e competências para planejar ações de ensino e de aprendizagem exequíveis e cumpridoras de seus objetivos é um dos pré-requisitos essenciais para a efetivação desse processo. Sem esses elementos, o professor fica impossibilitado de 
estabelecer um posicionamento propositivo enquanto agente promotor da aprendizagem para os alunos, sejam eles surdos ou não.

\section{REFERÊNCIAS}

ARTROLLI, A. L. A integração do aluno deficiente na classe comum: a visão do professor. Dissertação (Mestrado em Educação) - Programa de PósGraduação da Faculdade de Filosofia e Ciência, Universidade Estadual de São Paulo, Marilia, 1999.

BANDEIRA, G. M. Por que ensino como ensino? A manifestação e atribuição de origem de teorias informais no ensinar de professores de LE (Inglês).

Dissertação (Mestrado em Linguística Aplicada), Instituto de Letras, Universidade de Brasília, 2003.

BETTI, L. de C.; CAMPOS, P. R. I. Caminhos para uma educação inclusiva de alunos surdos: desafios para a gestão escolar. In: LACREDA, C. B. F.; SANTOS, L. F. dos; MARTINS, V. R. de. (Orgs.) O. Escola e diferença: caminhos para educação bilíngue de surdos. São Carlos: EdUFSCar, 2016, p. 29-44.

BRASIL. Lei n $^{\circ}$ 9394/96, de 20 de dezembro de 1996. Estabelece as diretrizes e bases da Educação Nacional. Disponível em

<http://www.planalto.gov.br/ccivil_03/leis/L9394.htm>. Acesso em 10 jul. 2018.

BRASIL. Lei $\mathbf{n}^{\circ}$. 10.436, de 24 de abril de 2002. Dispõe sobre a Língua Brasileira de Sinais - Libras e dá outras providências. Disponível em:

<http://www.planalto.gov.br/ccivil_03/leis/2002/l10436.htm>. Acesso em: 10 jul. 2018.

BRASIL. Decreto $n^{\circ}$ 5.626, de 22 de dezembro de 2005. Regulamenta a Lei no 10.436, de 24 de abril de 2002, que dispõe sobre a Língua Brasileira de Sinais Libras, e o art. 18 da Lei no 10.098, de 19 de dezembro de 2000. Disponível em <http://www.planalto.gov.br/ccivil_03/_ato2004-

2006/2005/decreto/d5626.htm>. Acesso em 16 abr. 2018.

BRASIL. Decreto $n^{\circ}$ 6.949, de 25 de agosto de 2009. Promulga a Convenção Internacional sobre os Direitos das Pessoas com Deficiência e seu Protocolo Facultativo, assinados em Nova York, em 30 de março de 2007. Disponível em <http://www.planalto.gov.br/ccivil_03/_Ato2007-

2010/2009/Decreto/D6949.htm>. Acesso em 10 ago. 2018.

BOUDON, R.; BOURRICAUD, F. Dicionário Crítico de Sociologia. São Paulo: Ática, 1993.

CARMO, A. A. Deficiência física: a sociedade brasileira cria, "recupera" e discrimina. Brasília: Secretaria dos Desportos/PR, 1991. 
CHARLOT, B. Da relação com o saber: elementos para uma teoria. Porto Alegre: Artmed, 2000.

COX, M. I. P. Pedagogias da língua: muito siso e pouco riso. Cad. Cedes, Campinas, vol. 24, n. 63, p. 135-148, maio/ago. 2004. Disponível em <http://www.scielo.br/pdf/ccedes/v24n63/22591.pdf>. Acesso em: 10 jul. 2018.

DAMILELLI, A. S.; CLASEN, J. H. L. Estudantes surdos: e agora professor? Rev. Técnico Científica (IFSC), v. 3, n. 1, p. 391-400. 2012.

ESTEVE, J. M. Mudanças sociais e função docente. In: NÓVOA, A. (org.) Profissão professor. $2^{a}$ ed. Porto, Portugal: Porto Editora, 1995.

GATTI, B. A. Análise das políticas públicas para formação continuada no Brasil, na última década. Rev. Bras. Educ., Rio de Janeiro, v. 13, n. 37, Abr. 2008.

GOOD, T. L. Teacher expectations and student perceptions: a decade of research. Educational Leadership. Washington, v. 38, n. 5, p. 415-22, 1981

JANNUZZI. G. S. M. A educação do deficiente no Brasil: dos primórdios ao início do século XXI. Campinas: Autores Associados, 2004.

KITZINGER, J. Focus groups with users and providers of health care. In: POPE, C.; MAYS, N. (Org.). Qualitative research in health care. 2. ed. London: BMJ Books, 2000, p. 33-44.

LACERDA, C. B. F.; LODI, A. C. B. A inclusão escolar bilíngue de alunos surdos: princípios, breve histórico e perspectivas. In: LODI, A.C.B.; LACERDA, C. B. F (Orgs.). Uma escola, duas línguas: letramento em língua portuguesa e língua de sinais nas etapas iniciais de escolarização. Porto Alegre: Editora Mediação, 2014, p. 11-33.

MARTINS, L. A. R. et al. Inclusão: compartilhando saberes. Petrópolis: Vozes, 2006.

MEIRIEU, P. O cotidiano da escola e da sala de aula: o fazer e o compreender, Tradução de Fátima Murad. Porto Alegre: Artmed, 2005.

MOURA, M. C. de. Surdez e linguagem. In: LACERDA, C. B. F.; SANTOS, L. F. (Orgs.). Tenho um aluno surdo, e agora? Introdução a Libras e educação de surdos. São Carlos: Edufscar, 2013. p. 13-26.

NÓVOA, A. (Coord.). Os professores e a sua formação. 2 ed. Lisboa: Dom Quixote, 1995.

OLIVEIRA, L. de F. M. de. Formação docente na escola inclusiva: diálogo como fio tecedor. Porto Alegre: Editora Mediação, 2009. 
PAJARES, M. F. Teacher's beliefs and educational research: cleaning up a messy construct. Review of Educational Research, v. 62, pp. 307-332, 1992.

PARIZZI, R. A. A pratica pedagógica do professor de educação especial: aprendendo a ensinar com a diversidade. Tese (Doutorado) - Programa de Pós-Graduação em Educação, Universidade Federal de São Carlos, São Carlos, 2000.

QUADROS, R. M. Educação de Surdos: a aquisição da linguagem. Porto Alegre: Artmed, 1997.

RAFAEL, E. L. Atualização em sala de aula de saberes linguísticos e formação: os efeitos da transposição didática. In: KLEIMAN, A. B. (Org.). A formação do professor: perspectivas da linguística aplicada. Campinas: Mercado das Letras, 2001, p. 157-180.

RAHME, M.; MRECH, L. M. Nomeação da diferença e inserção escolar: apontamentos para um debate sobre educação inclusiva e formação docente. Paidéia (Belo Horizonte), v. 5, n. 5, p. 23-45 jun./dez. 2008.

RAYMOND, A.M; SANTOS, V. Pre-service elementary teachers and selfreflection: how innovation in Mathematics teacher preparation challenges mathematics beliefs. Journal of Teacher Education, v.46, n. 1, jan/fev1995.

ROSENTHAL, R.; JACOBSON, L. Pygmalion in the classroom. New York, Rinehart and Winston, 1968.

SANTANA, A. P. Surdez e linguagem: aspectos e implicações neurolinguísticas. São Paulo: Plexus Editora, 2007.

SILVA, K.A. Crenças e aglomerados de crenças de alunos ingressantes em Letras (Inglês). Dissertação (Mestrado em Lingüística Aplicada), Instituto de Estudos da Linguagem, UNICAMP, Campinas, 2005

SILVA, V. G. da; ALMEIDA, P. C. de; GATTI, B. A. Referentes e critérios para a ação docente. Cadernos de Pesquisa. V. 46, n. 160, p. 286-31 1, abr./jun. 2016.

SKLIAR, C. Os estudos surdos em educação: problematizando a normalidade. In: SKLIAR, C. (Org.). A surdez: um olhar sobre as diferenças. Porto Alegre: Mediação, 1998.

TARDIF, M. Saberes docentes e formação profissional. Petrópolis: Vozes, 2002.

UNESCO. Declaração mundial sobre educação para todos. Plano de ação para satisfazer as necessidades básicas de aprendizagem. Tailândia, 1990.

UNESCO. Coordenadoria Nacional para a Integração da Pessoa Portadora de Deficiência (CORDE). Declaração de Salamanca de princípios, política e prática para as necessidades educativas especiais. Brasília: CORDE, 1994. 
Recebido em: 01 de julho de 2019 Aprovado em: 09 de outubro de 2019

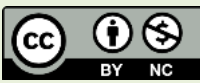

